\title{
Erratum zu: Die Entwicklung der Persönlichkeitsmarke
}

\section{Erratum zu:}

\section{Kapitel 3 in: C. Spall und H. J. Schmidt, Personal Branding,}

https://doi.org/10.1007/978-3-658-23741-7_3

Trotz sorgfältiger Erstellung unserer Bücher lassen sich Fehler nicht vermeiden, daher weisen wir auf Folgendes hin: Die Legende der Abb. 3.10 wurde korrigiert und der korrekte Copyright-Vermerk angebracht.

Die korrigierte Legende lautet: Abb. 3.10 Archetypen-Modell (Aus Hogshead 2015; mit freundlicher Genehmigung von (C) Redline Verlag, ein Imprint der Münchner Verlagsgruppe $\mathrm{GmbH}$. All rights reserved) 